\title{
Tantangan Pembelajaran Sejarah di Era Globalisasi
}

\author{
Oleh: \\ Hermanu Joebagio \\ Universitas Sebelas Maret Surakarta \\ Email: hermanu.joebagio@gmail.com
}

\begin{abstract}
Abstrak
Dampak globalisasi baik positif ataupun negatif tidak hanya dirasakan dalam bidang ekonomi, sosial, maupun politik. Adanya globalisasi juga memberikan pengaruh yang cukup signifikan dalam dunia pendidikan. Tujuan penulisan artikel ini adalah untuk mengetahui posisi pembelajaran sejarah dalam dunia pendidikan di era globalisasi dan menjelaskan mengenai pembelajaran sejarah yang inspiratif sebagai alternatif pembelajaran sejarah di era globalisasi. Dengan kompleksitas historis, dan globalisme telah melanda dunia, perlu mempertimbangkan inovasi dalam pembelajaran sejarah, yakni: (1) Menarik benang merah masa lalu ke dalam proyeksi masa kini. Masa lalu yang kelam maupun yang baik harus menjadi dasar proyeksi kita untuk melihat sejauhmana kebijakan yang telah dilakukan itu menunjukkan tindakan yang benar. (2) Era globalisme adalah era terbuka yang menuntut kita membangun kesadaran bahwa warisan sejarah bangsa yang terlukis dewasa ini tercermin dalam struktur sosial maupun struktur budaya. Kedua struktur itu merupakan aspek lokal yang dikagumi bangsa lain, dan tidak boleh dihancurkan, tetapi harus direvitalisasi untuk menghadapi globalisme.
\end{abstract}

\section{Kata kunci: pembelajaran sejarah, globalisasi, inovasi}

\begin{abstract}
The impact of globalization both positive and negative is not only felt in the economic, social, and political. The existence of globalization also gives a significant influence in education. The purpose of writing this article is to know the position of learning history in the world of education in the era of globalization and explain the learning of history as an alternative inspiration history in the era of globalization. With historical complexity, and globalism already engulfing the world, it is necessary to consider innovations in historical learning, namely: (1) Drawing past red threads into present-day projection. The dark past and the good must be the basis of our projection to see how far the policy that has been done shows the right action. (2) The era of globalism is an open era that requires us to build an awareness that the national heritage of today's painted country is reflected in the social structure as well as the cultural structure. Both structures are local aspects admired by other nations, and should not be destroyed, but must be revitalized to confront globalism.
\end{abstract}

Keywords: learning history, globalization, innovation 


\section{Pendahuluan}

Perubahan politik dari masa ke masa sangat berpengaruh terhadap kebijakan pendidikan nasional. Persoalannya, pergantian pimpinan selalu berinovasi yang membingungkan pengguna (stakeholders). Para pemimpin tidak mengedepankan penyusunan terhadap "cetak biru pendidikan nasional" yang digunakan sebagai upaya peningkatan mutu pendidikan, dan bersaing menuju mutu internasional. Indeks kualitas pendidikan nasional kita selalu berada di bawah indeks kualitas negara-negara tetangga. Meskipun kita telah memiliki Undang-Undang Sisdiknas, tetapi aplikasinya sangat lemah. Pergantian kurikulum KTSP 2006 yang belum mapan benar di lini operasional, harus diganti dengan Kurikulum 2013 yang tidak melalui uji coba produk kurikulum di sekolah yang ditunjuk. Kecenderungan 'terburu-buru' menimbulkan 'kesemrawutan' kerja para guru sekolah, bahkan kewajiban pembentukan sikap yang dipaksakan yang kemudian ditafsirkan beberapa pakar pendidikan membalikan landasan paradigmatik teori pendidikan.

Pada tiap jenjang pendidikan formal, baik sekolah dasar (SD), sekolah menengah pertama (SMP), hingga sekolah menengah atas (SMA), atau yang sederajat sangat jelas perbedaan landasan paradigmatiknya, terutama pada prosentase besaran bentukan pengetahuan-sikap-keterarnpilan pada jenjang itu. Yang paling sulit dihadapi para guru menghadapi pelaksanaan Kurikulum 2013 adalah para Guru IPS SMP yang harus memadukan komponen ajar ekonomi, geografi, sejarah, dan sosiologi secara terpadu. Belum lagi kewajiban untuk memasukkan nilainilai karakter yang tertuang pada Permendiknas, No. 22/2006.

Pada sisi lain, buku teks SMP/MTs Kelas VII Kurikulum 2013 menunjukkan pemaduan setengah dipaksakan dengan tema besarnya "Keadaan Alam dan Aktivitas Penduduk Indonesia", dan sub tema mengenai "Kehidupan Sosial Masyarakat Indonesia pada Masa Praaksara, Hindu-Buddha, dan Islam". Dikatakan setengah dipaksakan karena ada pemenggalari pembicaraan kehidupan sosial hanya sampai dengan masa datangnya Islam, sedangkan konstruksi kehidupan sosial terus berkembang melewati kurun waktu yang panjang. Sementara itu pada tema besar "Penduduk Indonesia dan Pemanfaatan Sumber Daya Alam" pada sub temanya sudah berbicara tentang mangrove adalah proses penataan lingkungan pantai implikasi dari indusrtialisasi dan modernisasi masyarakat. Saya menyatakan relasi antarsub tema bisa menimbulkan miskonsep sosial. Pertanyaan menarik dalam kaitan dengan seminar ini adalah bagaimana pembelajaran sejarah berhadapan dengan Kurikulum 2013 dan kondisi globalisme yang menekan itu? Apa yang harus dilakukan dalam jenjang pendidikan untuk memperjuangkan visi kesejarahan dan kebangsaan Indonesia?

\section{Metode Penelitian}

Metode penelitian yang digunakan dalam penelitian ini adalah metode penelitian kualitatif. 
Penelitian kualitatif merupakan satu kegiatan sistematis untuk menemukan teori dari kancah lapangan, bukan untuk menguji teori atau hipotesis. Dalam metode penelitian kualitatif, peneliti bahkan sebagai instrument utama yang mengadakan sendiri pengamatan, wawancara, dan pendokumentasian.

\section{Hasil Penelitian dan Pembahasan Globalisme dan Kurikulum Sejarah

Paradigma Kurikulum

Sejarah 2013 adalah konstruktivisme yang saya persepsikan tidak tunggal, karena di dalam konstruk itu juga berkeinginan memberi ruang bagi peserta didik untuk mengonstruksi pengetahuan sejarah, serta membentuk sikap humanis. Latar belakang munculnya paradigma itu adalah meluasnya degradasi moralitas bangsa dewasa ini. Paradigma yang baik dari kurikulum itu tidak diimbangi dengan persiapan yang matang. Konon, hasil wawancara dengan Guru Sejarah yang sudah melaksanakan maupun wawancara dengan salah seorang guru besar yang terlibat dalam proses penyusunan Kurikulum 2013 terdapat pemenggalan-pemenggalan konsep dalam proses penyusunan.

Bisa jadi akibat miskinnya "proporsional keahlian" dalam proses penyusunan. Semula pars guru berbahagia tidak membuat silabus dan RPP, karena sudah tersedia dalam buku panduan kurikulum, tetapi mereka terkejut ada ketidaksinkronan. Bila direnungkan terlihat paradoks karena aspek kontekstualitas dan kelokalan tidak mungkin dimasukan dalam struktur silabus dan RPP yang sudah tersusun. Fenomena di atas menunjukkan: (1) ketergesaan pemangku kebijakan dalam penyusunan maupun penerapan kurikikulum, (2) belum melalui uji coba secara baik untuk mendeskripsikan keunggulan dan kelemahan, (3) tampak dipaksakan dengan dana besar di atas satu trilliun, dan (4) membuat ragu sebagaian pakar pendidikan dan guru sejarah sehingga proses kegiatan pembelajaran dikelas dipersepsikan tidak akan menginspirasi peserta didik.

$\begin{array}{cc}\text { Semestinya } & \text { sebuah } \\ \text { kurikulum pada tiap jenjang }\end{array}$ pendidikan formal berpijak pada dua aspek: (1) analisis kebutuhan selaras dengan "jiwa zaman (zeitgeist) yang diinginkan pemangku kebijakan, dan (2) analisis kebutuhan peserta didik dalam menghadapi kompetisi dan kompetensi internasional yang selaras dengan perkembangan psikologi peserta didik. Hal ini penting, karena di era globalisme itu index standar kualitas pendidikan kita lebih rendah dibandingkan dengan index standar kualitas pendidikan negara tetangga.

Pada sisi lain, tersedianya silabus dan RPP saya pandang sebagai proses pembodohan terhadap guru. Silabus dan RPP itu akan diaplikasikan guru sejarah dalam penyusunan "sintak" atau "skenario" pembelajaran yang memuat aspek kontektualitas dan kelokalan. Sintak pembelajaran yang baik akan menginspirasi dan member peluang kepada peserta didik untuk mendekonstruksi peristiwa sejarah. Karena banyak materi sejarah yang digunakan sebagai "alat politik" sehingga sifatnya menjadi sangat 
kontroversial. Dekonstruksi perlu diperkenalkan kepada peserta didik untuk meningkatkan daya kritis mereka terhadap peristiwa sejarah, baik dalam perspektif temporal diakronik (kesinambungan antarperistiwa sejarah) maupun temporal sinkronik (suatu peristiwa yang berakibatkan perubahan sistem sosial-budaya, sosial-ekonomi, dan sosial-politik).

Dekonstruksi bila dijalankan secara baik akan berperan merevitalisasi materi ajar sejarah. Jacques Derrida dan Michel Foucault adalah dua tokoh poststrukturalisme atau post-modernisme yang mengemukakan bahwa sejarah sering digunakan sebagai "alat politik" penguasa untuk menyembunyikan kekejaman atau menghilangkan fakta sejarah yang mengindikasikan pencederaan nilai-nilai kemanusiaan (Ritzer, 2008). Peristiwa kudeta dan pembunuhan terhadap lawan-lawan politik sering dilakukan dan tidak pernah terungkap dalam pembelajaran sejarah. Asumsi ini selaras dengan pendapat Patrick Gardiner bahwa "historical events have an irreducible richness and complexity" (Gardiner, 1959:34).

\begin{tabular}{rrr}
\multicolumn{2}{r}{ Sebaliknya } & bila sejarah \\
dijadikan "alat & kontemplasi" \\
terhadap peristiwa & sosial yang
\end{tabular} pernah dihadapi manusia Indonesia di masa lalu, tentunya pembelajaran sejarah menjadi alat evaluasi untuk meniti kehidupan yang lebih arif dan bijaksana. Fenomena itu yang seharusnya menjadi bagian dari proses menanamkan nilai dalam pembelajaran sejarah. Guru sejarah akan mengatakan "kebenaran", dan tidak berpihak mengikuti garis politik pemerintah atau garis etnisitas dan religiositas yang dipercayainya. Dengan demikian dekonstruksi menjadi dasar membentuk sejarah masa kini, yang menafikan determinisme.

Di sisi lain, globalisme mempengaruhi sistem pendidikan kita, khususnya pembelajaran sejarah. Mengapa? Karena globalisme menuntut perubahan 'mind set' peserta didik. Karena implikasi dari globalisasi adalah tuntutan kesadaran terhadap ide-ide multikulturalisme, serta kearifan individu terhadap eksistensi nilainilai budaya lokal yang tidak berseberangan dengan akidah agama, dan masih hidup dalam masyarakat kita (Gardiner, 1959:34). Globalisme adalah kondisi dunia yang dipersepsikan tanpa sekat territorial sebagai akibat dari perkembangan teknologi dan komunikasi. Globalisme mendorong kemunculan sistem ekonomi dunia dan sistem politik yang demokratis (Gardiner, 1959:7-8). Bahkan globalisme sejatinya mempengaruhi budaya dan tradisi lokal yang telah disebutkan, dan berkehendak merubah budaya lokal melalui budaya McDonaldisasi yang liberal. Intrusi McDonaldisasi itu melalui kepariwisataan, serta media teknologi dan komunikasi. Bahkan intrusi itu merubah struktur politik yang dapat dilihat pasca pemerintahan orde baru, serta tumbuhnya tatanan ekonomi yang menafikan prinsipprinsip kerakyatan (Gardiner, 1959: 8).

Globalisme yang menguat pasca runtuhnya orde baru, menampilkan wajah baru paradoks, pada satu sisi menampilkan wajah kembali ke-shariah-an yang kental, bahkan berkeinginan mendirikan 
Negara Islam, dan pada sisi lain tuntutan demokrasi untuk membangun good governance (Bruinessen, 2013-1-20). Mengapa paradoks? Kembali ke-shariah-an dan mendirikan negara Isam dipersepsikan sebagai tindakan Arabisasi, dan tindakan itu berseberangan dengan citacita the founding fathers kita. Persepsi itu sudah menimbulkan gesekan, yang menumbuhkan polarisasi politik.

Pada sisi lain, berdemokrasi adalah wujud dari kehidupan merdeka dan berdaulat yang saling memberi ruang publik berinteraksi meskipun tidak sepaham dan berbeda orientasi politik. Dalam ruang publik yang merdeka dan berdaulat itu, maka demokrasi adalah bagian dari globalisme. Karena demokrasi berisi pengakuan terhadap perbedaan, sedangkan dalam giobalisme memberi makna terhadap kehidupan yang multikulturalisme. Bassam Tibi memandang meskipun suatu bangsa terdiri dari berbagai kultur berbeda, tetapi antarmereka memiliki jiwa solidaritas (Bassam Tibi, 2003: 1526). Praktik di Indonesia, globalisme berakibat tumbuhnya konflik atau friksi karena persoalan keberagaman etnisitas dan etnoreligiusitas yang sudah melekat dalam kehidupan bangsa kita. Namun, realitas konflik itu melekat pada dua persoalan, yakni: perbedaan akidah keagamaan, dan hasil pemilihan umum daerah.

Karut marut persoalan sosial-agama, sosial-ekonomi, dan sosial-politik bisa dimanfaatkan guru untuk merekonstruksi local wisdom baggage (bagasi kearifan lokal) dalam kegiatan pembelajaran sejarah. Bagasi kearifan lokal sesuai dengan Kurikulum 2013 adalah bagaimana guru dapat memberikan nilai-nilai moralitas kepada peserta didik. Sengkarut moralitas yang membelit birokrat dan politisi sungguh tidak lazim (out the box), dan perilaku mereka sangat menyakiti hati rakyat. Lantas bertanya apakah birokrat dan politisi kita semaunya sendiri, tanpa menghiraukan kehidupan rakyat, atau mengabaikan jati diri sendiri sebagai seorang "satria"?.

$\begin{array}{rr}\text { Sepanjang } & \text { pergerakan } \\ \text { bangsa hampir seluruh tokoh }\end{array}$ nasionalis berpegang pada jati diri "satria", dan bila disandingkan dengan realitas perilaku elit birokrasi dan politisi dewasa ini, sangat bertolak belakang. Bahkan H.S. Dillon menyebutkan elit politik reformasi tidak memiliki core values yang berbasis ideologi bangsa (Sudarmanta, 2012:xiii-x). Kalau begitu "sungguh terlalu" zaman reformasi yang sedang kita hadapi. Karena karakter birokrat dan politisi banyak yang out of box, tentu menjadi pijakan guru sejarah untuk menjadikan core values itu sebagai konstruksi sosial. Konstruksi sosial aspek penting dalam pembelajaran sejarah. Darin Weinberg mengemukakan konstruksi sosial adalah proses enkulturasi yang ditujukan untuk menyampaikan pesan terjadinya degradasi moralitas bangsa (Weinberg, 2012: 476-487).

Ketika Soekarno berkuasa, dia menolak keras investasi modal asing yang ditujukan untuk mengeksploitasi hutan Indonesia, karena hutan paru-paru bagi bangsa Indonesia. Fenomena keteladanan Soekarno perlu dienkulturasi dan diwariskan kepada peserta didik, karena dia ingin mendidik rakyat 
tidak merusak alam. Kalaupun alam akan dieksploitasi perlu mempertimbangkan eko-sistemnya, sehingga tidak terjadi kerusakan yang merugikan bangsa. Dengan begitu terbentuk awareness atau kepedulian peserta didik sepanjang proses pembelajaran.

\section{Pembelajaran Sejarah yang Menginspirasi}

Globalisme menuntut perubahan 'mind set' bangsa, mengingat globalisasi b'erimplikasi pada tumbuhnya multikulturalisme yang akan mempengaruhi nilai-nilai kearifan lokal kita (Turner, 1994:183-184). Peran guru sejarah dalam membentuk awareness harus melalui terobosan dengan membuat 'framing strategy' (strategi mewacanakan tema tertentu yang dilanjutkan dengan penggalian wacana). Dengan begitu 'framing strategy' menjadi pijakan tumbuhnya awareness. Untuk dapat melaksanakan "framing strategy" perlu mendekonstruksi materi sejarah. Sebagai contoh, guru sejarah membuat 'framing strategy' dalam tema islamisasi, yang menyampaikan kepada peserta didik mengenai peran Sultan Agung dalam membangun harmoni dengan melakukan rekonsiliasi antara Islam dan budaya Jawa. Kebijakan itu intinya, keraton sebagai pusat kajian agama Islam, dan Islam sebagai payung budaya Jawa (Ricklefs, 1998:469-482). balam pandangan Sultan Agung bahwa budaya Jawa perlu diperkuat dengan akidah Islam untuk menekan unsur-unsur budaya yang tidak selaras dengan ajaran Islam. Kesadaran Sultan Agung bila dienkulturasi dan diwariskan dalam proses kegiatan pembelajaran sejarah rnenumbuhkan konstruksi sosial baru berbentuk kesadaran dan kepedulian terhadap multikulturalisme yang diayomi oleh unsur agama.

Sejatinya 'framing strategy' merupakan dekonstruksi terhadap materi ajar maupun metode pembelajaran konvensional. Dengan 'framing strategy' dan proses pembelajaran yang membangun kepedulian, dalam paradigma pemikiran Bassam Tibi dapat menumbuhkan civilization selfawareness (Bassam Tibi, 2003:1526). Tumbuhnya kepedulian ataupun kesadaran disebut Paulo Freire sebagai "culture circle", yang merubah konsep pasif menjadi aktif melalui keterampilan profesional guru sejarah (Paulo Freire, 2005:38). 'Culture circle' bukan budaya sekolah, tetapi sistem instruksional yang disusun secara terstruktur yang memuat kegiatan dialog, diskusi, dan klarifikasi suatu tema masalah antarkolompok belajar (Paulo Freire, 2005:38).

Merrill Harmin dan Melanie Toth mengemukakan langkah menumbuhkan kepedulian peserta didik adalah:

(1) Tidak ada tindakan dari guru atau peserta didik untuk mempermalukan anak didik atau teman sejawat. Tahap ini disebut dignity.

(2) Memberi ruang kepada peserta didik untuk mencari pasangan dialog secara kelompok, serta mempersiiahkan mereka memilih topik 'framing' yang disampaikan guru. Tahap ini disebut energy and self management.

(3) Guru menyusun sintak pembelajaran yang berisi 
kegiatan terstruktur pembelajaran tersebut berpijak pada Permendiknas No. 41/2007 yang meliputi: (a) pembukaan; (b) kegiatan ini berisi eksplorasi, elaborasi, dan konfirmasi; dan (c) penutup. Struktur kegiatan ini bersifat penggalian yang diwacanakan melalui dialog dan diskusi dengan peer student. Tahap ini disebut community. Pada tahap ini sintak pembelajaran mengeksplorasi sistem sosial, sistem reaksi, dampak instruksional, dampak pengiring, dan sistem pendukung.

Sistem sosial adalah patokan yang disusun guru dengan harapan peserta didik dapat menguasai ilmu pengetahuan melalui transfer of knowledge yang dilakukan, membangun interaksi antarpeserta didik, guru, lingkungan, dan sumber belajar. Aspek terpenting dari proses ini adalah bagaimana peserta didik dapat menginternalisasi peristiwa dan mengklarifikasi nilai-nilai yang terkandung dalam peristiwa sejarah, baik karakter pelaku sejarah maupun karakter peristiwa itu sendiri. Sistem reaksi merupakan rangsangan yang dilakukan guru sejarah agar tujuan pembelajaran tercapai. Stimulus tumbuh bila proses pembelajaran terorganisasi dengan baik, khususnya: (1) tema bahasan memiliki daya tank bagi peserta didik, (2) diorganisir dalam kelompok belajar, dan (3) dievaluasi baik proses maupun hasilnya. Tiga komponen itu dalam konstruktivisme Piaget dan Vygotsky, mempermudah peserta didik melakukan diskusi kelompok, karena masing-masing peserta didik telah memiliki sejumlah informasi dari berbagai pengalaman. Informasi itu, meskipun antarmereka berbeda, tetapi dapat ditularkan dalam diskusi sebagai simpulan fenomena peristiwa sejarah (Akbar \& Sriwiyana, 2010: 196).

Dampak instruksional merupakan implikasi proses pembelajaran sejarah yang diharapkan meningkatkan: penguasaan kompetensi sejarah, (2) pengembangan sikap meliputi penghargaan dan bertindakan secara positif, dan (3) pengembangan keterampilan sosial peserta didik yang terwujud dari tindakan yang dilakukan selama proses pembelajaran berlangsung. Melalui ketiga komponen itu diharapkan dapat memetik keteladanan dari topik/tema sejarah yang disajikan. Dampak pengiring timbul apabila proses pembelajaran sejarah memberi kontribusi terhadap penguatan nilai yang berdampak terhadap Iingkungan sosial peserta didik. Sistem pendukung adalah perangkat dan alat bantu yang digunakdn guru sejarah dalam proses pembelajaran. Yang dimaksud dengan sistem pendukung adalah RPP, lembar evaluasi, lembar latihan lanjutan, dan alat bantu pembelajaran Iainnya.

\section{Penutup}

Pembelajaran sejarah dewasa ini tidak dapat diajarkan secara kronologi dan tekstual, tetapi harus dirubah dengan cara guru agar peserta didik tumbuh awareness dan berpikir kritis atau berpikir historis. Karena itu sistem instruksional harus direncanakan guru dengan baik. Sistem instruksional terinci dalam sintak atau skenario pembelajaran, sehingga keaktifan peserta didik 
tampak, dan interaksi pembelajaran itu yang memungkinkan tumbuhnya awareness.

\section{Ucapan Terimakasih}

Dalam kesempatan ini, penulis mengucapkan terimakasih kepada berbagai pihak yang telah membantu terlaksananya penelitian tindakan kelas ini, sejak dimulainya penelitian, penyusunan hasil penelitian dan publikasi .Tidak lupa pula, ucapan terima kasih penulis sampaikan kepada dewan redaksi Jurnal Istoria yang diterbitkan oleh Fakultas Ilmu Sosial Universitas Negeri Yogyakarta atas kesempatan, bantuan dan kerjasamanya yang tidak terhingga sehingga hasil penelitian ini dapat dipublikasikan pada edisi Maret 2017.

\section{Referensi}

Akbar Hadi Sriwiyana. 2010. Pengembangan Kurikulum clan Pembelajaran IPS. Yogyakarta: Cipta Media.

Bruinessen, Martin Van. 2013. Contemporary Developments in Indonesian Islam. Singapore: ISEAS.

Freire, Paulo. 2005. Education for Critical Consciousness. London \& New York: Continuum.

Gardiner, Patrick. 1959. Theories of History. New York: The Free Press.

J.B. Sudarmanta. 2012. An Indonesian Renaissance: Kebangkitan Kembali Republik Perspektif H.S. Dillon. Jakarta: Buku Kompas.

Ricklefs, M.C. 1998. "Islamising
Java: The Long Shadow of Sultan Agung", Archipel, Vol. I, No. 56.

Ricklefs, M.C. 1998. "Islamising Java: The Long Shadow of Sultan Agung", Archipel, Vol. I, No. 56.

Ritzer, Geogre \& Douglas J. Goodman. 2008. Teori Sosiologi Modern. Jakarta: Kencana Prenada Media.

Tibi, Bassam. 2003. Islam and the West: Dialogue of Civilization in Search of a Peaceful Global Order. Jakarta: Pusat Bahasa dan Budaya U1N Syarif Hidayatullah \& Konrad Adenauer Stiftung.

Turner, Bryan S. 1994. Orientalism, Posmodernism, and Globalism. London \& New York: Routledge.

Turner, Bryan S. 2012. Teori Sosial: Dari Klasik sampai Postmodern. Yogyakarta: Pustaka Pelajar. 